\title{
Analysis of Operation Mode for Complex DHS
}

\author{
Girts Vigants $^{1}$, Ivars Veidenbergs ${ }^{2}$, Gundars Galindoms $^{3}$, Edgars Vigants ${ }^{4}$, Dagnija Blumberga ${ }^{5},{ }^{1-5}$ \\ Riga Technical University
}

\begin{abstract}
The overall effectiveness of DHS operation depends on the effectiveness of each element of the system separately, as well as on the interaction of all elements which can be evaluated by definite parameters on the operation of the system. The results, which comprise some most essential parameters, reveal that the impact of the temperature of supply and return water does not impact on the total efficiency of the system. Special attention is paid to losses in the heating network in cases with or without a flue gas condenser.
\end{abstract}

Keywords - Gas condenser; energy efficiency improvement; heat supply system; heating network; climate technology

\section{INTRODUCTION}

In Latvia, the district heating systems (DHS) play a significant role, supplying about $80 \%$ of users with heat energy. This is economically cost effective from many points of view, as it is possible to achieve a higher efficiency of the energy production, at the same time taking into account heat losses in DHS. Another advantage of compact DHS is the possibility to use the wholesale trade principle, since all the expenses forming the tariff per MWh produced in a large system are comparatively lower [1,2]. DHS are very similar; they are composed of three elements:

- a heat source;

- heat networks;

- heat consumers.

The Latvian experience shows that the overall efficiency of the DHS is very different, reflected heat consumer tariffs. Heat rates differ by more than two times. Difference in tariffs of different district heating companies gives reason to study their components and to talk about the need to implement energy effectiveness measures on-site in energy production plants [3], as well as the need to replace expensive fossil fuels with relatively cheaper domestic biomass (basically wood) [4,5].

Within the heat power source, it is of utmost importance to choose the economically and ecologically most appropriate resource - the fuel. For instance, from all perspectives it is most appropriate in Latvia to have a complex DHS, which includes an essentially ramified chain of heat consumers and a boiler house (basic fuel - wood chip), at which it is possible to deeply cool flue gases at a flue gas condenser. At the largest cities of Latvia, natural gas is available. It is an imported fossil fuel, which is economically justified to use as a reserve fuel, for instance, during maintenance of wood chip boiler [6]. The use of wood chips entails also the following negative aspects comparatively expensive technologies, necessity for a storage place, but the main problem is that the use of it often is with a low efficiency. This can especially be observed in furnaces that burn damp wood. Wood chips can have widely differing levels of moisture content, from the $25 \%$ standard envisioned by the European Union to snow-covered wood with a moisture content of over $55 \%$ and sometimes even $60 \%$. There are two ways of increasing the effectiveness of a boiler house relying on wood chips as fuel:

1. To dry the wood chips before feeding them into the furnace. The organisation of the drying process depends on the specific needs of the boiler room. A dryer must be used to obtain wood chips with low moisture content, but dryers consume relatively large amounts of energy that cannot be used for other purposes.

2. The installation of a flue gas condenser behind the boiler system [7]. The deep cooling of flue gases implies that these gases are to be cooled below the dew point. Technologically, this means that proper conditions should be provided for this process, i.e. allowing the condensation of vapours contained in flue gases [8]. The operation of a gas condenser depends on the energy effectiveness of the connected DHS users, as well as on water speeds and flow parameters in all the elements of a heat network including the heat exchangers at the heat substations of the buildings. In order to raise the amount of heat derived from a gas condenser, it is necessary to reduce the DHS return water temperature. This could be done by modelling - qualitatively and quantitatively - the operating conditions and control of the heat-supply system $[1,9]$.

If compared to individual heat supply systems, the main 'weak point' of the DHS is the losses of heat power during its transportation. This problem cannot be completely solved. Heat losses at the heat network can be reduced by thoroughly inspecting the technical condition of the heat network, by applying the qualitatively quantitative system of regulation, and by operating the DHS with as low temperature of the heat carrier as possible $[9,10]$.

It is correct to plan in a long-term perspective - to maximally optimize the DHS so that the heat losses at the heat network and at the heat consumers are as low as possible, but consumption of fuel is reduced to the maximum extent possible at the heat source. Latvian economic rationale of the complex DHS system encompasses an essentially ramified chain of heat consumers and a boiler house, at which it is possible to deeply cool flue gases at a flue gas condenser.

\section{RESEARCH METHODOLOGY}

A complex district heating system (DHS) is a system encompassing an essentially ramified chain of heat consumers and a boiler house, at which it is possible to deeply cool flue gases at a flue gas condenser. 
Experience shows that generally the effectiveness of operation of a heating system depends on the effectiveness of each separate element:

- efficiency of an energy source;

- heat losses in heating network;

- energy effectiveness of a heat consumer.

The effectiveness of a DHS is also significantly influenced by the correlation of all three said components, which can be evaluated by employing the particular parameters of operation of the system:

$$
\eta_{\text {DHS }}=\mathrm{f}\left(\mathrm{t}_{\text {supply }} ; \mathrm{t}_{\text {return }} ; \mathrm{G}_{\mathrm{DHS}} ; \mathrm{t}_{\mathrm{fg}} ; \alpha ; \mathrm{CO} ; \mathrm{q}_{\text {loss }} ; \mathrm{q}_{\text {cons }} ; \mathrm{t}_{\text {const }} ; \mathrm{t}_{\mathrm{ot}} ; \mathrm{W} ; \mathrm{A}\right)(1)
$$

where

$\eta_{\text {DHS }}$ - efficiency of heating system;

$\mathrm{T}_{\text {supply }}$ - temperature of supply water in heating network;

$\mathrm{T}_{\text {return }}$ - temperature of return water in heating network;

$\mathrm{G}_{\mathrm{DHS}}$ - flow rate at heat supply system;

$\mathrm{T}_{\mathrm{fg}}$ - temperature of flue gases at the chimney opening;

$\alpha$ - air consumption ratio at the chimney opening;

$\mathrm{CO}$ - concentration of carbon monoxide in flue gases;

qloss - heat losses in the surrounding environment;

qcons - specific energy consumption of heat consumers;

$\mathrm{t}_{\text {cons }}$ - consumer temperature at a heat substation;

W - wood wetness contents;

A - wood ash contents;

$\mathrm{T}_{\text {out }}$ - outdoor temperature.

The methodology for DHS operation analysis, the algorithm of which is described in this article, includes using the described equation system into modeling the effectiveness of a complex DHS.

The effectiveness evaluation methodology for the DHS, as proposed in this work, is based on the data analysis of one heating season of Ludza DHS. The operation data for years 2012/2013 are analyzed, and results of the analysis are obtained in the form of correlation equations, which are further used in calculations. Correlation equations are examined in more detail in this work [11]. In the article [11] it is demonstrated, that, upon a condition that a fuel gas condenser is installed at the boiler house, the efficiency of a system may be calculated by using the following expression:

$$
\eta_{\text {sys }}=\eta_{\text {boiler }}\left(1+\mathrm{N}_{\text {cond. }} / \mathrm{N}_{\mathrm{cap}}-\mathrm{Q}_{\mathrm{hl}} / \mathrm{N}_{\mathrm{cap}}\right) \text {, }
$$

where

$\eta_{\text {boiler }}$ - boiler efficiency;

$\mathrm{N}_{\text {cond.- }}$ condenser capacity, $\mathrm{MW}$;

$\mathrm{N}_{\text {cap }}$ - boiler capacity, MW;

$\mathrm{Q}_{\mathrm{hl}}$ - heat loss in heating network, MW.

Figure 1 demonstrates changes efficiency of district heating system depending on outdoor temperature, with and without a condenser.

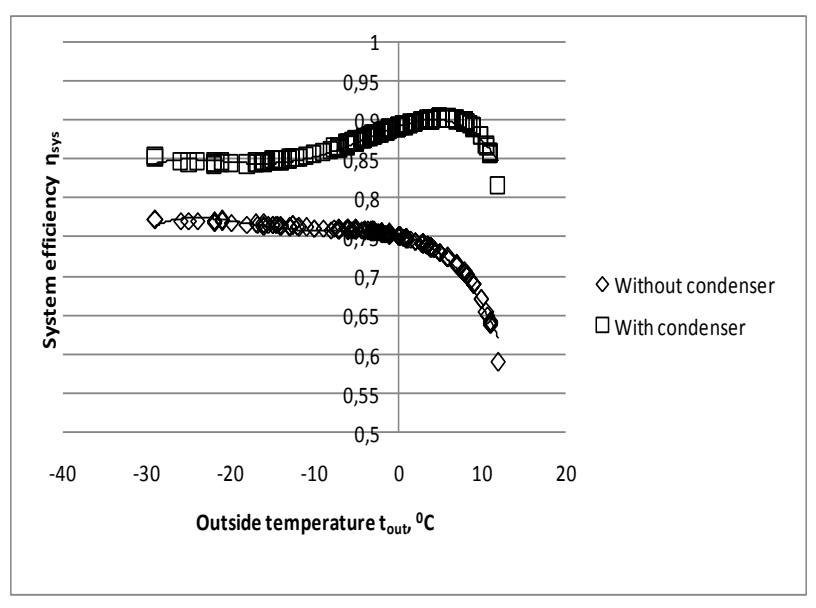

Fig. 1. Changes in efficiency of district heating system depending on outdoor temperature

The effectiveness of operation of a complex DHS depends on outdoor temperature. Moreover, in case the flue gas condenser is used, the efficiency increases if outdoor temperature is above $0^{0} \mathrm{C}$

\section{ANALYSIS OF RESULTS}

From expression (2) it can be seen, that, in case the efficiency of a boiler does not change, then the efficiency of the system is determined by changes in relative relations of condenser capacity and heat. Changes in relations are demonstrated graphically in the form of curves in Figure 2.

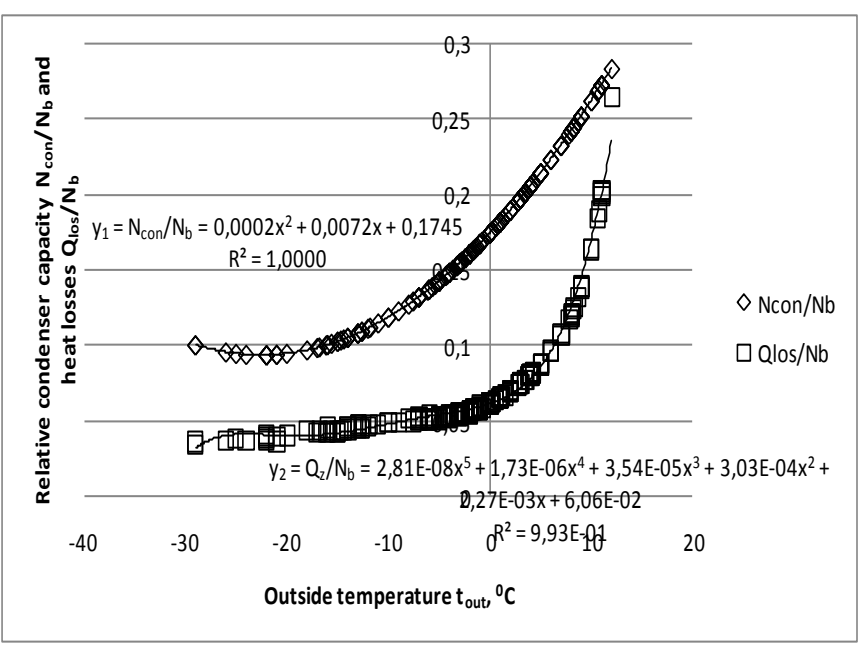

Fig. 2. Changes in relative condenser capacity and network heat losses depending on outdoor temperature.

Equations describing changes in relations can be found in Figure 2.

The relative condenser capacity increases the capacity supplied into the heating main, however relative heat losses decrease it. It can be seen that the character of temperature curves varies at different temperatures. Relative capacity of condenser increases by square, if outdoor temperature grows. Increase in relative losses is small, if outdoor temperature grows approximately to $0 \ldots 3{ }^{0} \mathrm{C}$. Within this interval of temperatures, the relative capacity supplied into the main 
exceeds the relative losses, and therefore the efficiency of the system rises, as can be seen in Figure 1. Further increase in outdoor temperature is related to a substantial increase in relative heat losses. This causes a decrease in efficiency.

The qualitative changes of relative parameters referred to herein, may be characterized quantitatively with the help of a gradient curve. The gradient of a curve at a given point is defined to be the gradient of the straight line that touches the curve at that point. The gradient of the curve at point is equal to the tangent at that point. In case the equation of the curve is known, then the gradient can be determined by differentiating the expression, for instance, the gradient for relative curve of condenser capacity is:

$$
\mathrm{dy}_{1} / \mathrm{dx}=\mathrm{d}\left(\mathrm{N}_{\mathrm{con}} / \mathrm{N}_{\mathrm{b}}\right) / \mathrm{dt}_{\mathrm{out}}=0.0004 \mathrm{t}_{\text {out }}+0.0072
$$

The gradient of a curve is determined by differentiating the graphical expression of relative losses demonstrated in Figure 2.

$$
\begin{aligned}
\mathrm{dy}_{2} / \mathrm{dx}= & \left.\mathrm{d}\left(\mathrm{Q}_{\mathrm{z}} / \mathrm{N}_{\mathrm{b}}\right) / \mathrm{dt}_{\text {out }}=1 \cdot 4 \cdot \mathrm{E}^{\wedge}(-7)\left[\mathrm{t}_{\text {out }}\right]\right]^{\wedge} 4+6.92 \mathrm{E}^{\wedge}(-6)\left[\mathrm{t}_{\text {out }}\right]^{\wedge} 3+ \\
& +1.06 \mathrm{E}^{\wedge}(-4) \cdot\left[\mathrm{t}_{\text {out }}\right]^{\wedge} 2+6.06 \mathrm{E}^{\wedge}(-4) \cdot \mathrm{t}_{\text {out }}+2.27 \mathrm{E}^{\wedge}(-3)
\end{aligned}
$$

By using equations (3) and (4), the values of curve gradients are calculated and pictured graphically in Figure 3.

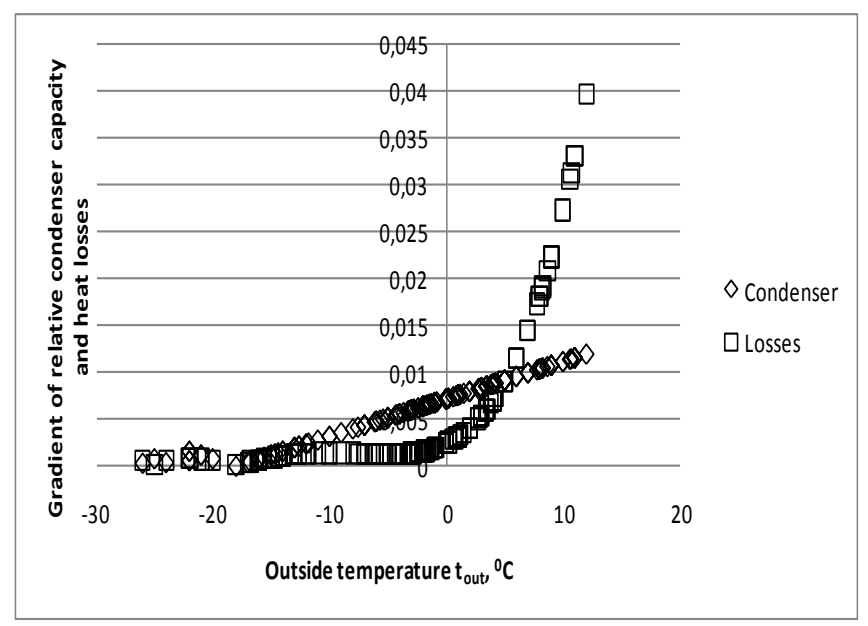

Fig. 3. Changes of curve gradient values depending on outdoor temperature

It can be seen in this Figure, that in case temperature grows up to approximately $-15^{\circ} \mathrm{C}$, the gradients are $\mathrm{dy}_{1} / \mathrm{dx}=\mathrm{dy}_{2} / \mathrm{dx}$. The curves of relative condenser capacity and heat losses in Figure 2 are parallel, and curves of system usefulness efficiencies in Figure 1 are without changes as well, in addition to which it should be noted that in case the condenser is used, the values of efficiency are higher. In case temperature grows from $-15^{\circ} \mathrm{C}$ up to approximately $+4^{0} \mathrm{C}$, a coherence $d y_{1} / d x>d y_{2} / d x$ is valid, and relative condenser capacity supplied into the heat network exceeds the relative heat losses, as demonstrated in Figure 2. Within this range of outdoor temperatures the system efficiency grows. In case outdoor temperature grows above $+4^{0} \mathrm{C}$, the proportion of gradients changes, and is $\mathrm{dy}_{1} / \mathrm{dx} \quad \mathrm{dy}_{2} / \mathrm{dx}$. This means, that the relative value of heat losses grows quicker that the relative value of condenser capacity, and as it can be seen from Figure 1 , the value of efficiency of the heat supply system decreases. In case outdoor temperature is approximately $+4^{0} \mathrm{C}$, the values of gradients are equal, growth in system efficiency cannot be detected, and it has the maximum value.

Changes in efficiency of the system without the flue gas condenser depending on the outdoor temperature, as demonstrated in Figure 1, are steady without extreme, and its value diminishes, in case outdoor temperature rises above $0^{\circ} \mathrm{C}$. In order to assess the efficiency, the equations presented in this work can be used by applying value of the condenser capacity $\mathrm{N}_{\mathrm{con}}=0$.

\section{CONCLUSIONS}

1. Operation effectiveness of the complex heat supply system of Ludza depends on the outdoor temperature, and it increases, in case temperature grows above $15^{\circ} \mathrm{C}$, and reaches maximum, in case temperature is $+4^{0} \mathrm{C}$.

2. Changes in system effectiveness are determined by the changes in relative condenser capacity and heat losses depending on the outdoor temperature.

3. It is demonstrated that values of gradient curves can be used for quantitative assessment of relative changes in condenser capacity and heat losses.

4. Changes in efficiency for a system without a flue gas condenser depending on the outdoor temperatures, are steady without extreme, and its value decreases, in case outdoor temperature rises above $0^{0} \mathrm{C}$.

\section{REFERENCES}

1. Blumberga D., Vīgants E., Veidenbergs I., Vīgants G., Vītoliṇš V., Eco-intensity analysis for a chip-fuelled boiler house, Journal of Environmental Engineering and Landscape Management, 2012, (4) pp. 249-255.

2. Chungen Yin, Lasse A. Rosendahl, Søren K. Kær, Grate - firing of biomass for heat and power production, Progress in Energy and Combustion Science, Institute of Energy Technology, Aalborg University, DK-9220 Aalborg East, Denmark 34, 2008, pp. 725-754.

3. Difs, K., Trygg, L., Pricing district heating by marginal cost, Energy $\begin{array}{llllll}\text { Policy, } & \text { pp. } & 606 & - & 616, & 37,\end{array}$ http://dx.doi.org/10.1016/j.enpol.2008.10.003

4. Okkonen, L., Suhonen, N., Business models of heat entrepreneurship in Finland, Energy Policy 38, pp.3443 - 3452, 2010. http://dx.doi.org/10.1016/j.enpol.2010.02.018

5. Madlener, R., Innovation diffusion, public policy, and local initiative: The case of wood-fuelled district heating system in Austria, Energy Policy, 35, 2007, pp. $1992 \quad-\quad 2008$ http://dx.doi.org/10.1016/j.enpol.2006.06.010

6. Vīgants G., Ivanova P., Vīgants E., Veidenbergs I. Analysis of Diversification of Fuel in DH Sources. Potential of Reduction of GHG, The 13th International Symposium on District Heating and Cooling (DHC13), Denmark, Copenhagen, 3.-4. September, 2012. - pp 179-285.

7. Vīgants E., Blumberga D., Veidenbergs I., Vīgants G., Rochas C. Experimental Research of Flue Gas Condensing Unit, Advances in Environment, Biotechnology and Biomedicine: Proceedings of the 1st WSEAS International Conference on Energy and Environment Technologies and Equipment, Czech Republic, Zlin, 20.-22. September, 2012. - pp 179-189

8. Vīgants E., Blumberga D., Veidenbergs I., Climate Technology in a Wood Chips Boiler House, Scientific Journal of Riga Technical University. 13. series., Environmental and climate Technologies. - 6. vol. 2011, pp 127-131.

9. Vīgants G., Blumberga D. Modelling of the District Heating System's Operation, Scientific Journal of Riga Technical University. 13. series., Environmental and climate Technologies. - 6. vol. 2011, pp 132-137. 
10. Henrik Gadd, Sven Werner, Heat load patterns in district heating substations, Applied Energy 108, 2013, pp. 176-183. http://dx.doi.org/10.1016/j.apenergy.2013.02.062

11. Vīgants G., Galindoms G., Veidenbergs I., Blumberga D., Energy efficiency of DH system with wood chips boiler houses and flue gas condensing unit, Proceedings of the 2013 International Conference on Energy, Environment, Ecosystems, and Development (EEED 2013), Rhodes island, Greece, July 16-19, 2013, Energy, Environmental and Structural Engineering Series, Vol. 12, 2013, pp. 168 - 171.

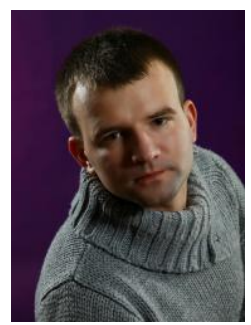

Girts Vigants, Mg.sc. ing., SIA "Balteneko". Mr. Vigants has been working in SIA "Balteneko" since 2003. His main activity field is project leading and implementation. He has implemented fossil energy transition to renewable in Adazi, Latvia. He has participated in different local projects related to energy and environment. $\mathrm{He}$ has Professional Bachelor Degree in Heat, Gas and Water Systems and Engineer qualification in Heat, gas and Water Technology (2010) and Professional Master Degree in Heat, Gas and Water Systems (2011). In his Master Thesis he has researched calculation optimization of district heating pipelines for constant and variable flows. Currently he is $\mathrm{PhD}$ student at Riga Technical University.

Address: S. Eizensteina 29, LV - 1079, Riga, Latvia

E-mail: girts.vigants@rtu.lv

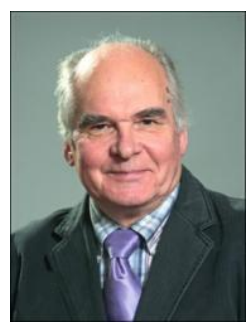

Ivars Veidenbergs, Dr.Hab., professor, Institute of Energy Systems and Environment, Riga Technical University. Doctor Habilitus Thesis "Engineering Methods for Calculating Heat and Mass Transfer in the devices of Power Units" was defended in RTU, 1992. PhD thesis "Dynamic Temperature Regimes of Thermoelectric Cooling Devices" was defended in RPI, now RTU, 1975. First degree in Thermal Engineering (thermal equipment of thermal power stations) (Moscow State University of Railway Engineering), 1960. The main research area is energy and environment. He is author of more than 180 publications and 5 books.

Address: Kronvalda bulv. 1, Riga, LV-1050

E-mail: ivars.veidenbergs@rtu.lv

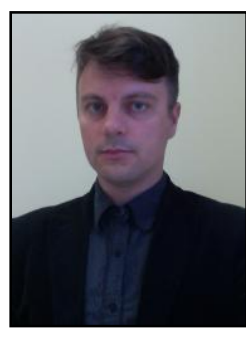

Gundars Galindoms, Master, PhD student (since 2012), Institute of Energy Systems and Environment, Riga Technical University (RTU). Master Degree in Environmental Science, RTU, 2012. First degree in Computer Science, RTU, 2001. Research interests: cogeneration, renewable energy resources, energy efficiency and climate technologies.

Address: Kronvalda bulv. 1, Riga, LV-1050

E-mail: gundars.galindoms@rtu.lv

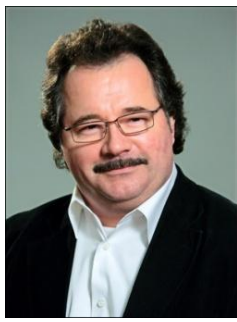

Edgars Vigants, Dr.sc.ing., docent of Institute of Energy Systems and Environment, Riga Technical University (RTU). Member of the board, SIA "Ludzas Bio-Energija", Latvian Bio Energy Association. Doctor of Environmental Science, RTU, 2012. First degree in Heating, Gas and Ventilation Systems Construction Engineering (RPI, now RTU), 1983. Research interests: cogeneration, renewable energy resources, energy efficiency and climate technologies.

Address: Kronvalda bulv. 1, Riga, LV-1050

E-mail: edgars.vigants@rtu.lv

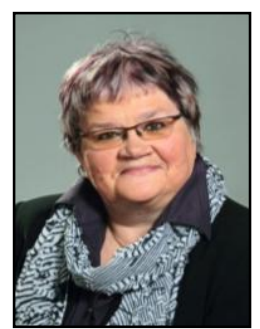

Dagnija Blumberga, Dr.Hab., professor and director of institute, Institute of Energy Systems and Environment, Riga Technical University (RTU). Doctor Habilitus Thesis "Analysis of Energy Efficiency from Environmental, Economical and Management Aspects" was prepared in Royal Institute of Technology (KTH), 1995 and was defended in RTU, 1996. $\mathrm{PhD}$ thesis "Research of Heat and Mass Transfer in Gas Condensing Unit" was defended in Lithuanian Energy Institute, 1988. First degree in Thermal Engineering (RPI, now RTU), 1970. The main research area is renewable energy resources. She has participated in different local and international projects related to energy and environment as well as she is author of more than 200 publications and 14 books.

Address: Kronvalda bulv. 1, Riga, LV-1050

E-mail: dagnija.blumberga@rtu.lv 